\title{
The Munich Bikeability Index: A Practical Approach for Measuring Urban Bikeability
}

\author{
Jonas Schmid-Querg, Andreas Keler*DiD and Georgios Grigoropoulos
}

\author{
Chair of Traffic Engineering and Control, Technical University of Munich (TUM), 80333 Munich, Germany; \\ jonas.schmid-querg@tum.de (J.S.-Q.); george.grigoropoulos@tum.de (G.G.) \\ * Correspondence: andreas.keler@tum.de
}

\begin{abstract}
This research addresses the phenomenon of varying bicycle friendliness in urban areas and considers which elements are necessary to design a city in a bike-friendly manner. It aims to provide a deeper understanding of the term bikeability, in relation to the established term walkability, and methods to create models that measure the degree of bikeability in urban areas. We explain different established models and compare their computational bases. The focus of this paper is to define a computational methodology built within a Geographic Information System (GIS) and a subsequent evaluation based on an investigation area in Munich, Germany. We introduce a bikeability index for specific investigation areas and geovisualize four selected factors of this index. The resulting map views show the road segments of the traffic network where the conditions for biking are adequate, but also those segments which need to be improved.
\end{abstract}

Keywords: urban transportation; spatial analysis; bicycle infrastructure; vulnerable road users; bikeability; bicycle friendliness

check for updates

Citation: Schmid-Querg, J.; Keler, A.; Grigoropoulos, G. The Munich Bikeability Index: A Practical Approach for Measuring Urban Bikeability. Sustainability 2021, 13, 428 https://doi.org/10.3390/su13010428

Received: 16 November 2020 Accepted: 30 December 2020 Published: 5 January 2021

Publisher's Note: MDPI stays neutral with regard to jurisdictional clai$\mathrm{ms}$ in published maps and institutional affiliations.

Copyright: $\odot 2021$ by the authors. Licensee MDPI, Basel, Switzerland. This article is an open access article distributed under the terms and conditions of the Creative Commons Attribution (CC BY) license (https:// creativecommons.org/licenses/by/ $4.0 /)$.

\section{Introduction}

An increasing number of people are using bicycles daily, to explore their advantages for commuting between various locations, to conduct shopping activities, or as a means for leisure time including tourist activities [1]. As opposed to motorized private transport, bicycles are more environmentally friendly, cheaper, and health enhancing, and may also be more time efficient for short to medium long routes in urban areas [2].

Nowadays, bicycles are not only a means for reaching a destination but rather a trend for expressing a certain way of life, representing an environmentally and health-oriented conscience [3]. This socio-cultural phenomenon becomes evident through a rising share of bicycles in the modal split [4]. Both, the global climate and the local environment are profiting from this change through reduced carbon dioxide (CO2) emissions (global) and, respectively, nitrogen oxides (NOx) emissions (local), and thus an improved air quality [5]. Bicycle infrastructure needs significantly less space and is cheaper as compared with other means of transport [6], which is especially beneficial in metropolises with their characteristic problems of scarce spaces. Current developments have included introducing user-adaptive systems for human-electric bikes to increase ridership, such as by Lee and Jiang [7], which might benefit the comfort of urban cycling with novel technologies usually experienced in motorized individual transport.

Over the years, many studies have explored all types of traffic-related aspects with regard to the motorized individual transport, much less with regard to bicycles and their role in traffic $[8,9]$.

The goal of this work is to provide an overview of the possibilities for measuring the degree of how suitable urban regions are for biking. We identify the contributing factors and explain existing methods with indices for measuring bikeability. The focus of this approach, however, is on the creation of our own experimental bikeability index for a specific part of the city of Munich based on applying GIS methodologies. We conclude with 
result visualizations and a discussion on the strengths and weaknesses of the approach for the case studies conducted in Munich, Germany.

The main contribution of this work consists of introducing a novel bikeability index with specific benefits in selected applications. One advantage of this index consists of its efficient and simple computation and the ability to adapt to the specific static components of various investigation areas. The index is useful for detecting spots of low bikeability on road networks with different spatial extents.

\section{State-of-the-Art Bikeability}

The word "bikeability" is a relatively novel term, used in various scientific articles [10-12] but not yet implemented in reputed dictionaries. The Merriam-Webster and Oxford Dictionary only include the term "bikeable" and define it as "suitable or fit for biking" [13] and, respectively, "suitable or safe for cyclists" [14].

Different definitions from various authors exist, however, many do not work concisely, and thus vague understandings of the term emerge. The most precise definition appears to be one by Lowry et al. [15]. Bikeability is "an assessment of an entire bikeway network for perceived comfort and convenience and access to important destinations" [15]. They differentiate bikeability, bicycle suitability, and bicycle friendliness. Bicycle suitability is "an assessment of the perceived comfort and safety of a linear section of a bikeway". Hence, bikeability is a superordinate concept, spatially and content related. Bicycle friendliness embodies aspects of bikeability, and it refers to an evaluation by a community [16] regarding different aspects of biking such as laws and policies, education efforts, and the acceptance of cycling $[17,18]$.

According to Nielsen et al. [19], bikeability is an indexation of the environment in which cycling is taking place and how the examined area supports choosing the bicycle as a mode of transport. The elements of the indexation are of an infrastructural (including proximity to access to other modes of transport) and topological manner [19]. In general, planning and implementing bicycle infrastructure in urban environments is challenging [20] and may make use of complex optimization techniques [21]. Other approaches have focused on evaluating a present bicycle infrastructure by observing cyclists [22] and relating extracted patterns $[23,24]$, such as route preferences [25], to the underlying road network structure [26].

Other research has focused on the level of stress experienced by cyclists in selected environments, which has been extracted via surveys concerning the level of stress along routes [27]. This is described as a user-centered approach as personal views on traversed bicycle infrastructures are being evaluated [28]. Because data on perceived safety can be assessed [29], various views on bicycle traffic safety [30] may be incorporated into bikeability estimations [31]. This is of paramount importance when observing mode choices of daily commuters [32].

On a broader level, the presence of bike sharing services [33] are incorporated into a selection of environmental factors [34], which may become more important in future studies on estimating bikeablity indices of various urban environments [35]. Additionally, present and future bicycle courier services may benefit from calculating bikeability indices for improving their service qualities [36].

\subsection{Measuring and Modeling Bikeability}

The bikeability of a city or district can be analyzed with certain methods. Various models or indices exist, which try to classify the bikeability using selected criteria. As the indices do not always encompass the same criteria, there can be different weighting or usage approaches, and results may not be consistent for the same city.

In the following subsections, we briefly explain four existent indices, and derive a clustering of these approaches. 


\subsubsection{The Copenhagenize Index}

Initiated by the Copenhagenize Design Company, in 2011, this index ranks the 136 most bicycle-friendly cities in the world. It encompasses 14 categories in which cities can obtain zero to four points, as well as bonus points for special effort. This index refers to cities as a whole and does not differentiate between different districts in the publicly available results. The entire analysis likely represents the business case by selling the information to the cities. The components are as follows [37]:

1. Lobbying of non-governmental organizations (NGOs);

2. Bicycle culture (how well are bicycles established among citizens);

3. Bike facilities (availability of parking spaces, ramps, designated spaces in trains;

4. Bicycle infrastructure;

5. Bike-sharing programs;

6. Gender split (percentage of men and women that use bicycles);

7. Modal split;

8. Modal split increase of bikes since 2006;

9. Safety perception (the perception that cycling is safe);

10. Politics (political involvement in promoting bikeability);

11. Social acceptance (feelings of car drivers towards cyclists);

12. Urban planning;

13. Traffic abatement (efforts that have been made to implement slow traffic zones);

14. Freight bicycles and logistics.

\subsubsection{Bicycle Level of Service}

Another possibility is the approach via the "bicycle level-of-service" (BLOS) [38], developed by Lowry et al. [15]. This rather recent method calculated the bicycle suitability using the bicycle level-of-service of the Highway Capacity Manual (HCM) which delivered a BLOS value for linear and linked street segments by certain criteria such as width of bike lane, vehicle traffic volume, vehicle speed, and pavement condition. Then, this BLOS value was enhanced by the concept of accessibility for calculating bikeability.

This variable is modeled by the well-known equation:

$$
A_{i}=E_{j} \times f\left(r_{i j}\right)
$$

where $A_{i}$ represents the accessibility of a location $I ; E_{j}$ the importance of a destination $j$; and $f\left(r_{i j}\right)$ an impedance function for travel time, distance, or costs $r_{i j}$ from $i$ to $j$.

The result is a spatial feature (grid cell) that is a decimal number between zero and one, those with close destinations as well as those with good BLOS routes have a high bikeability. The analysis is GIS-based and the result is a grid-based map representation of bikeability [15].

This is the only index that contains the concept of accessibility. It is solely based on spatial data, and thus is reliant on its quality. The authors remark that sufficient data is not available for all streets, which is why, in this case study, our own field assessment and estimations have been carried out for some criteria. This implicates a rather high effort for bigger cities should this method be used elsewhere.

\subsubsection{The "ADFC Fahrradklimatest" in Germany}

Every two years the ADFC (Allgemeiner Deutscher Fahrradclub, General German Bicycle Association) gathers data to assess the bicycle friendliness in many cities. According to its own statement, the survey is the largest in the world and, in 2016, more than 120,000 people from 539 cities took part [39]. The approach is not based on quantitative but rather on qualitative information obtained from individual valuations of the test subjects as everyone is able to take part in an online questionnaire regarding the following topics:

1. Cycling and traffic climate;

2. Safety for cyclists; 
3. Family friendliness;

4. Comfort for cyclists;

5. Infrastructure and network of designated bike paths;

6. Status of bicycle traffic.

Every question is rated from good to bad and a number from one to six is generated. Thus, the perceptions of many people form the public opinion of bicycle friendliness. Perceptions are subjective, hence, the accuracy of a data-based analysis of traffic infrastructure cannot be met by this approach. Furthermore, it is only possible to create an image of the whole city, and not of different districts where improvement might be critical. Specific demand for action cannot be evaluated locally.

\subsubsection{Bikeability Index Dresden}

This index visualizes the bikeability with regular spatial grid cells with the dimensions of $100 \times 100 \mathrm{~m}$. This is the only available resolution for bikeable zones. It is an additive index, which calculates a number via adding values for different criteria for each grid cell. This number is the bikeablity of the respective cell. The grid cell information for every criterion is addressed via weighted overlay analysis, which originates from McHarg [40] and is related to map algebra [41]. The following components are solely hard factors and do not entail supplementary measures such as political agendas [42]:

1. Bicycle infrastructure (bike paths and lanes);

2. Existence of structurally-separated bike paths;

3. Green area and water surface;

4. Topography;

5. Land use;

6. Bicycle facilities;

7. Traffic load.

Within the criterion topography, steep terrain slopes reduce the number of people willing to use bicycles, as the effort to reach destinations is regarded as uncomfortable. In this case study, all criteria have been weighted equally, thus, the importance of certain aspects may not be valued sufficiently. This index does not include accessibility. Nevertheless, the included aspect of land use analysis is taken into account via densities of potential destinations within grid cells.

\subsection{Theoretical Approaches of Bikeablity Indices and Literature Classification}

Firstly, models that include solely hard factors of bikeability (infrastructure and bicycle facilities) can be differentiated from those that consider soft factors, such as organizational and supplementary, but not constructional measures such as events and political agendas of cities. This is the underlying difference between bikeability and bicycle friendliness. Secondly, there are two different methods of information gathering, i.e., technical analysis of infrastructure (own assessments or external procurement of data stored in geodatabases) and public surveys. The former is factual, and the latter represents the perception of traffic participants. The third stage would be the resolution of the model, whether it is city-levelor grid-based model (e.g., based on $100 \times 100 \mathrm{~m}$ cells). The grid-based or choropleth map-based model gives an opportunity to visualize bikeability in certain districts of a city. Models working with geodatabases mostly have higher spatial resolutions, although supplementary factors often cannot be incorporated at this level. The fourth and last stage would be the consideration of accessibility as it is considered in Lowry et al. [15]. It is not especially a hard nor a soft factor and surpasses the connectivity, as certain places may be linked to attractive destinations by a very good bike path, although this path is several kilometers long.

If a municipality aims to locally analyze its strengths and weaknesses regarding bikeability, available literature reveals that often available data sources related to the built infrastructure or population are formed into grid-based data aggregations with manually assigned resolutions [43], whereas both data models, raster-based and vector-based, can be 
used to achieve the same end product. In the case of GIS-based visualization of bikeability, there is the possibility of targeting selected locations within an investigation area where changes in bikeablity might be expected. This can be introduced by extracting local knowledge or via spatial analysis results when selected bikeability-related measures are being compared with their spatial distributions. In the case that information regarding bicycle friendliness for a spatially defined administrative area is available, a potential data analyst might introduce specific measures or weightings for all spatial units of this area. This means that the input information for estimating bikeability will be introduced in great detail, not on a local level but on a contentual level. Taking this into account, it is important to focus on the road segment representations of available transport networks, as additional public survey data may be associated with road elements with longer polyline segments that, then, may result in altering information representation. A common case of generating falsified information attached to road segments could occur from the analysts by unreasonably matching additional information onto road segments. This possibility could be an important bikeablity index estimation design factor, as available literature reveals the more frequent appearance of city-based and grid-based bikebility indices over those with a networked-based bikeablity indices. An overview of four methodologies found within a literature review is shown in Figure 1, where the general types of factors are divided (red and green arrows), and whether the index is a city- or grid-based index is also indicated.

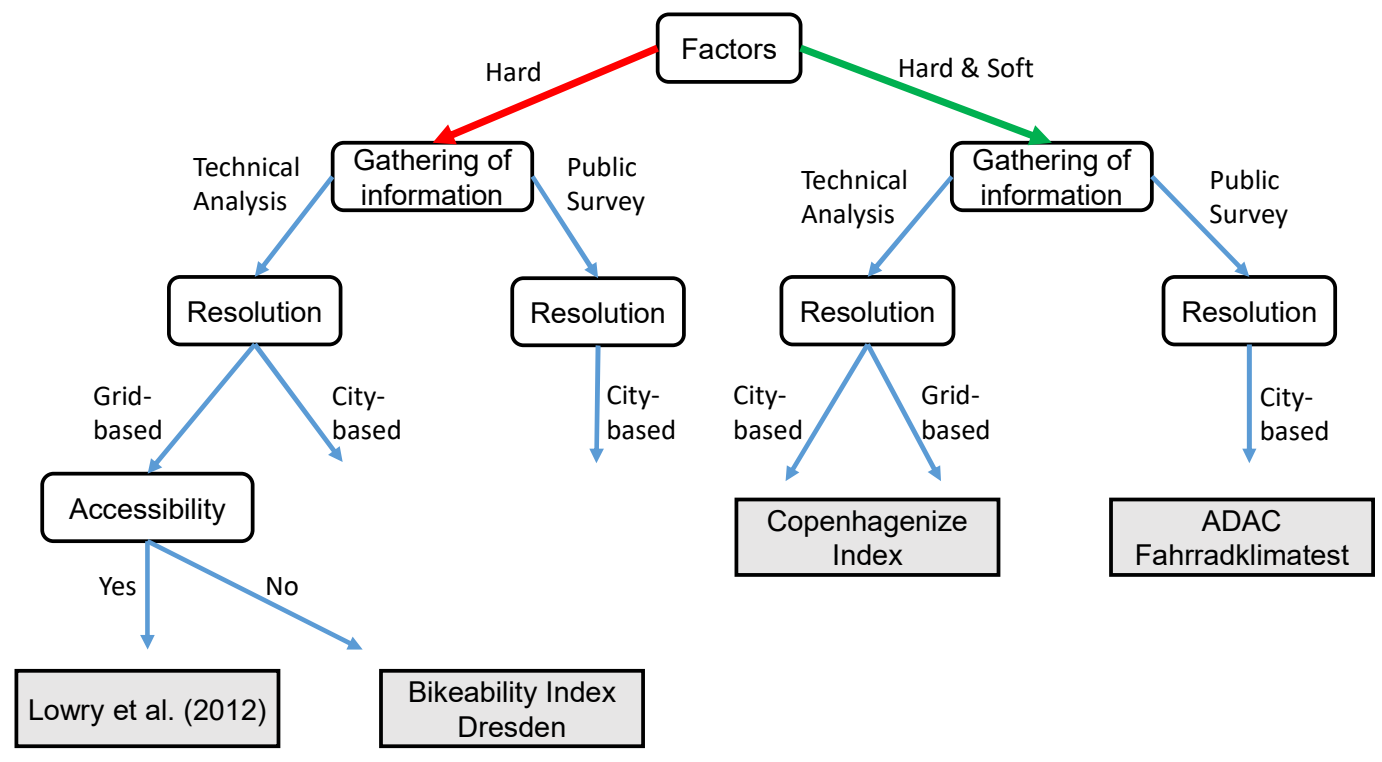

Figure 1. Classification of selected bikeability indices (own depiction).

The purpose of Figure 1 is to validate a pattern of the bikeability index literature classification. Therefore, the presented bikeability and bicycle friendliness indices are categorized following their theoretical approach in the diagram in Figure 1.

The resolution of a grid-based index is scalable if the underlying data is sufficient, thus, it can also deliver average values for districts of the whole city, not just the single grid cells. An index that only evaluates hard factors such as infrastructure and bicycle facilities via public survey could not be found.

In addition to the above-mentioned approaches, there are approaches for calculating a cycling comfort index using data gathered from tracked bicycles equipped with various sensors, such as by Zhu and Zhu [44]. This shows the numerous possibilities of how to elaborate on different influencing factors coming from static and dynamic data sources. For example, Gholamialam and Matisziw [45] used origin-destination pairs of cycling trips for assigning zones and paths of varying bikeability. 


\section{Case Study in Munich, Germany}

In this section, a part of a district in the inner city of Munich, Germany, is analyzed regarding its bikeability based on the following four factors:

1. Existence and type of bike path;

2. Speed limit;

3. Parking facilities for bicycles;

4. Quality of intersection infrastructure for bicycles.

The creation of this index is solely based on our own field assessment and mapping of the testing ground. We used a GIS software or GIS-based methodologies to process the available data and developed a map product of visualized bikeability.

\subsection{The Investigation Area for Testing Bikeability Estimation}

The investigation area is pictured in Figure 2 and is part of the densely structured road network of the Munich city district Maxvorstadt with three major roads in west-east directions. Additionally, these road segments in the center of Munich, Germany, connect three universities, i.e., Schelling-, Theresien-, and Gabelsbergerstraße. It can be stated that these locations are characterized by commuting cyclists, especially during the daytime in summer seasons.

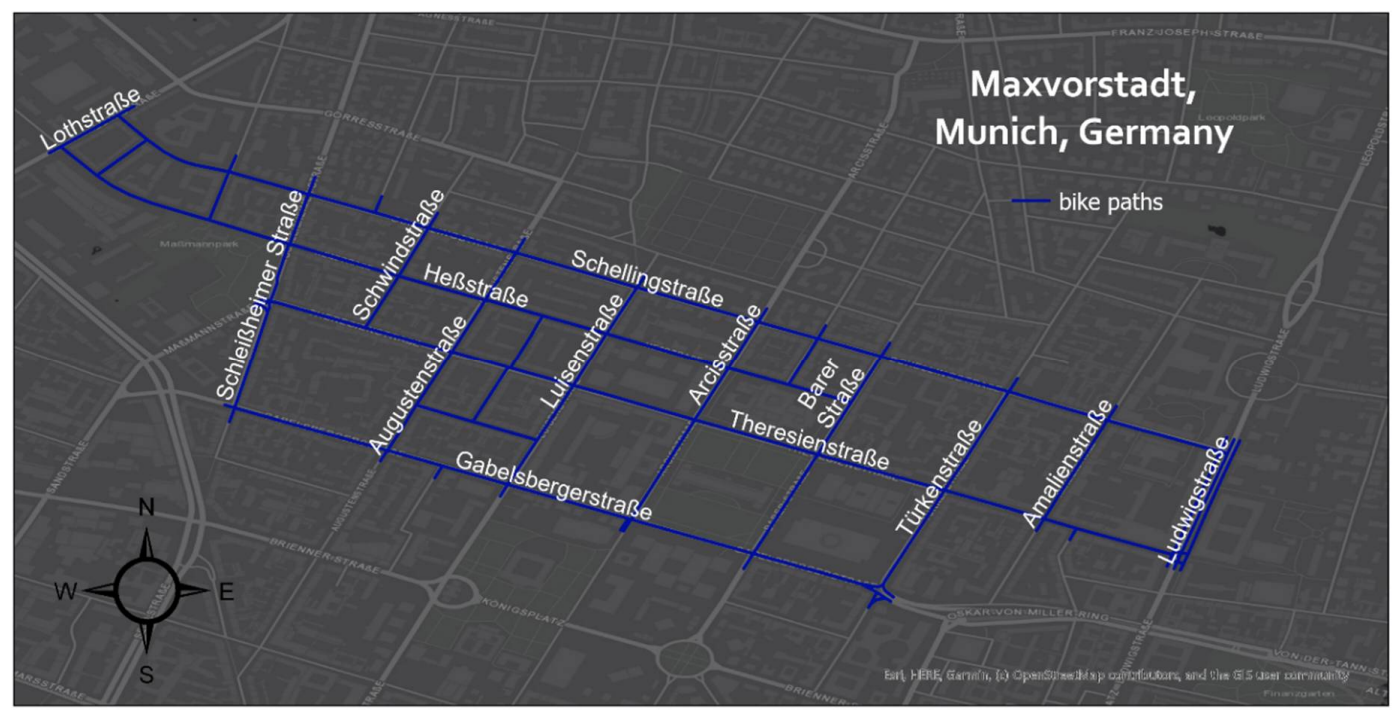

Figure 2. Investigation area in Maxvorstadt, Munich, Germany.

The reason for selecting this particular area in Munich is based on the assessed local knowledge, the available geodata, and our own field assessment that we have a low concentration of implemented bicycle infrastructure in this area as compared with most other parts of Munich. Numerous bike lanes are only present at parts of the selected roads in the map view in Figure 2. Additionally, bike paths are only available at a few of these roads. In our expectation, only a few roads in Munich have a low bikeability index, as in this area pictured in Figure 2. There are numerous segments indicating mixed traffic modes, whereas the rest of Munich has often additional bicycle infrastructure.

\subsection{Methodological Approach}

The above street grid was procured from maps based on Open Street Map (OSM) data [46]. Although the OSM data extracts contained data layers that categorized streets, bike paths, and bicycle parking, after first visual analyses, those were not complete or categorized consistently. Therefore, as previously mentioned, we reviewed the testing ground, categorized the existing infrastructure, and created evaluation scales for the criteria. 
The basis for the categorization and how the scores were determined came mainly from field observations and interviews or questionnaires from commuters at selected study areas. Because, in our approach, statistically significant outcomes from the conducted interviews are difficult to infer, we focus on obtaining qualitative data from persons with an extensive local knowledge of the investigation area. This guarantees that our method is applicable within other investigation areas by interviewing commuting cyclists with a local knowledge of the respective investigation area. Dependent on this, we assumed representative abilities of this group of interviewees for evaluating and classifying attributes of the perceived bikeability.

Within the conducted interviews, several aspects of bikeability were defined as preselected with the purpose of performing an attribute weighting by interviewees experienced in cycling at the inspected investigation area (interviewees with extensive local knowledge). This is a qualitative data acquisition procedure that aims at focusing on the needs of local cyclists only. The last question for every interviewee was to complete missing aspects of the factors influencing local bikeability, referring to missing and not listed attributes. It should be stated that the procedure of conducting the interviews could be altered or improved, which would significantly impact the actual defined scores.

As attributes are only weighted by the answers of interviewees who are very familiar with the investigation area, we expected a broad knowledge of the influencing factors during cycling and the experienced traffic situations related to these factors. Therefore, the weighting of the attributes by active cyclists was considered to be the most detailed from the view of a cycling road user. However, individual experience could be influenced by the qualitative comparison to the surrounding areas. Therefore, we conducted interviews with commuters who had their trip origins or destinations in the selected investigation areas.

Depending on the factors being associated by most commuters, we define four basic layers (bike paths, speed limit, bicycle parking, and intersections) and enrich road network representations with information on the respective criterion. The street segments of the first three layers receive attributes with an integer value between 1 and 10, the fourth layer (intersections) is a point-by-point assessment, as it is not referring to the whole street network. The evaluation scales for the different criteria are listed in the appendix.

Bicycle infrastructure, such as constructional separated bike paths, appears to be the most fundamental criteria in most indexes for both safety and safety perception. A speed limit is elemental as well for bikeability, as safety is increased because of the breaking distance. In addition, noise exposure decreases with lower speeds, which can be fundamental for the perceived safety of cyclists [47]. Bicycle parking is crucial in order to safely store bikes from theft and weather if possible. Depending on the number of parking spots, the sphere of influence was sized accordingly. Evaluations of intersections are rarely found in bikeability indices, nonetheless it is highly important as, especially, turning maneuvers pose a greater risk for accidents (especially left turns), and thus designated infrastructure that prioritizes cyclists increases their safety [48].

Subsequently, we transferred separate layers to raster data with a conversion function of converting polylines into raster cells with a resolution of $1 \mathrm{~m}$. This step originated from the aim to address different spatial scales via aggregation methodologies for raster data. Additionally, we introduced this disaggregation step for future attempts to incorporate additional bikebility factors on a higher spatial resolution scale, where we could incorporate locations of static and partially dynamic objects, for example, those related to construction sites as delineator posts. This means that we disaggregate due to incorporating surface areas with a $1 \mathrm{~m}$ cell resolution that might be classified as potential obstacles for cyclists. These could also be related to partially dynamic phenomena such as parked cars on infrastructure assigned for cyclists. As a result of this conversion step, then, the quality of every street segment could be visualized for each criterion independent of the shape of a certain road segment. For the actual bikeability index, we conducted a weighted overlay analysis comparable to the implementation of Mayfield et al. [49] and left it open as to how this weighted overlay could be adjusted. As we focused on evaluating the weighting schemes 
based on short interviews or questionnaires with the views of commuters and predefined map views with varying weighting schemes, we left this part of the methodology open for multiple possible weighting options depending on the available data.

The distributions of the final scores and the score differences of each attribute are a result of the conducted interviews with experienced cyclists with local knowledge. The interviewees ranked each attribute using numerical values from 1 to 10 , and this ranking mostly resulted from an average of received answers. As a result, a speed limit of $50 \mathrm{~km} / \mathrm{h}$ (7) has a higher rank than the presence of both-sided bike lanes (6). It should be state that this is investigation-area specific and could vary with every built environment, the selected interviewees, and their present local knowledge.

As an outcome, we represented the raster data with varying significances in different map views, which are explained in the following subsection.

\subsection{Inspected Parameters and Resulting Map Views}

The visually inspected parameters for the Munich bikeability index within resulting map views are shown in Figures 3-6. The evaluation scales are explained in Tables A1-A4.

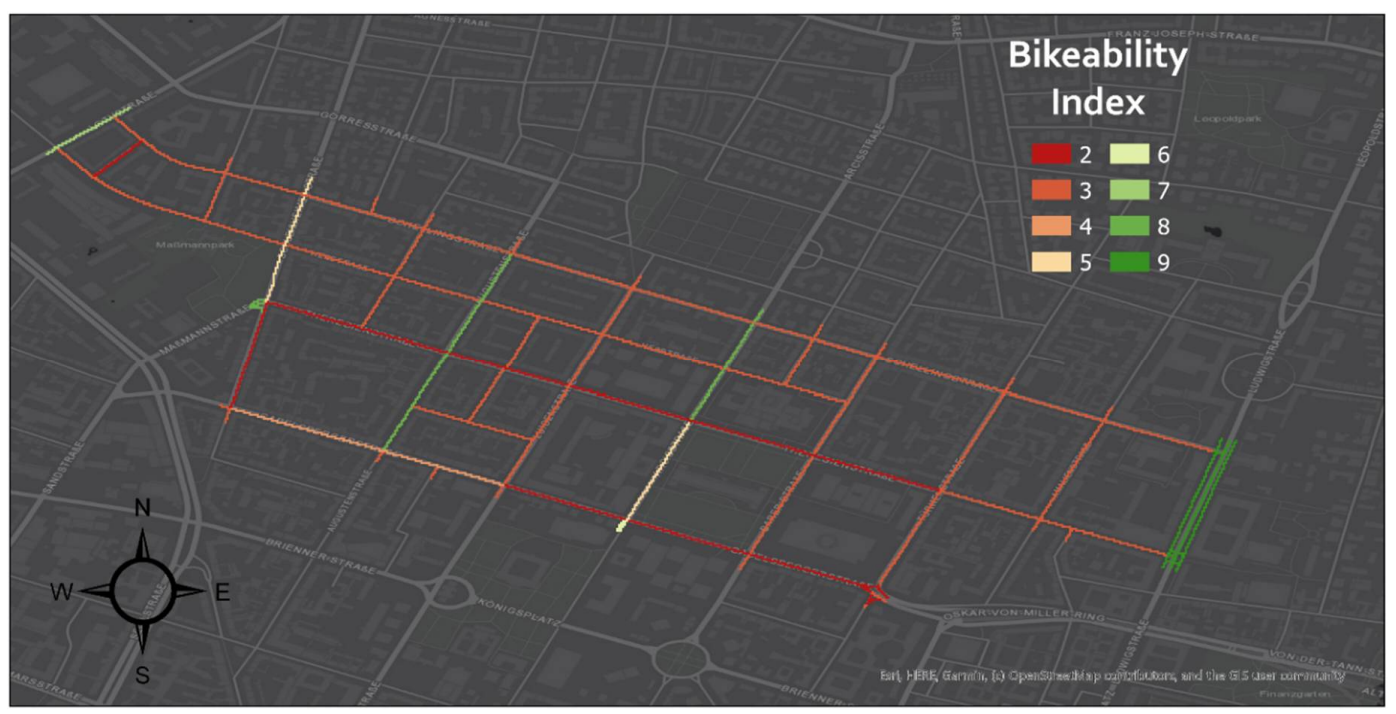

Figure 3. Evaluation of bicycle infrastructure.

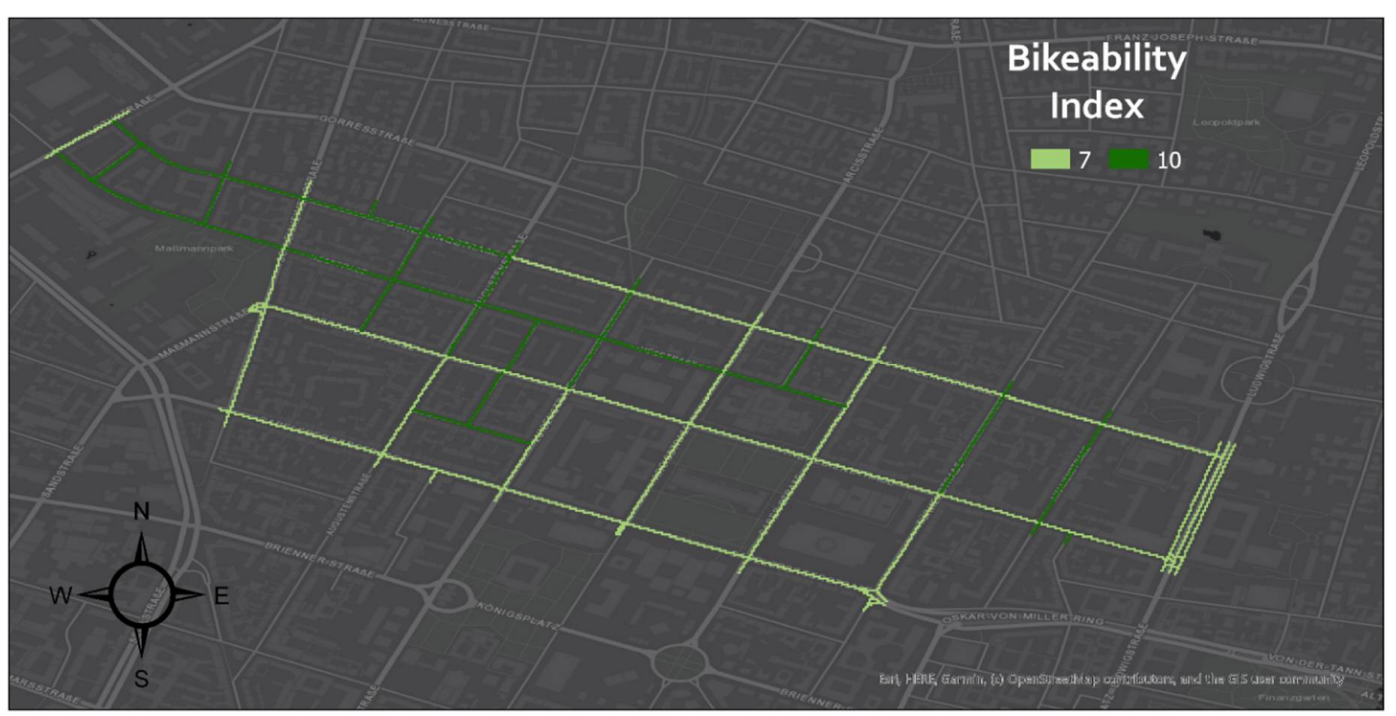

Figure 4. Evaluation of speed limits. 


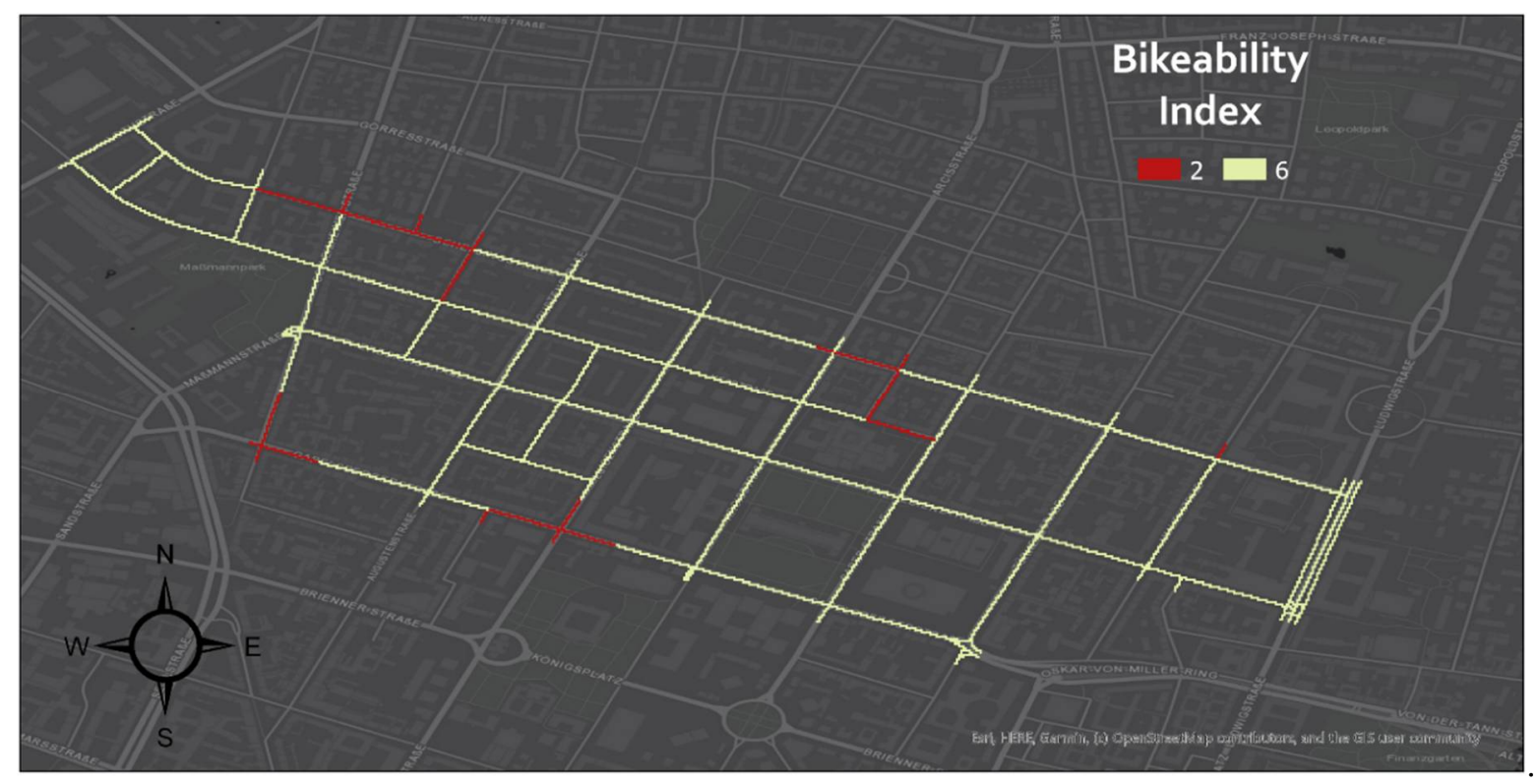

Figure 5. Evaluation of bicycle parking.

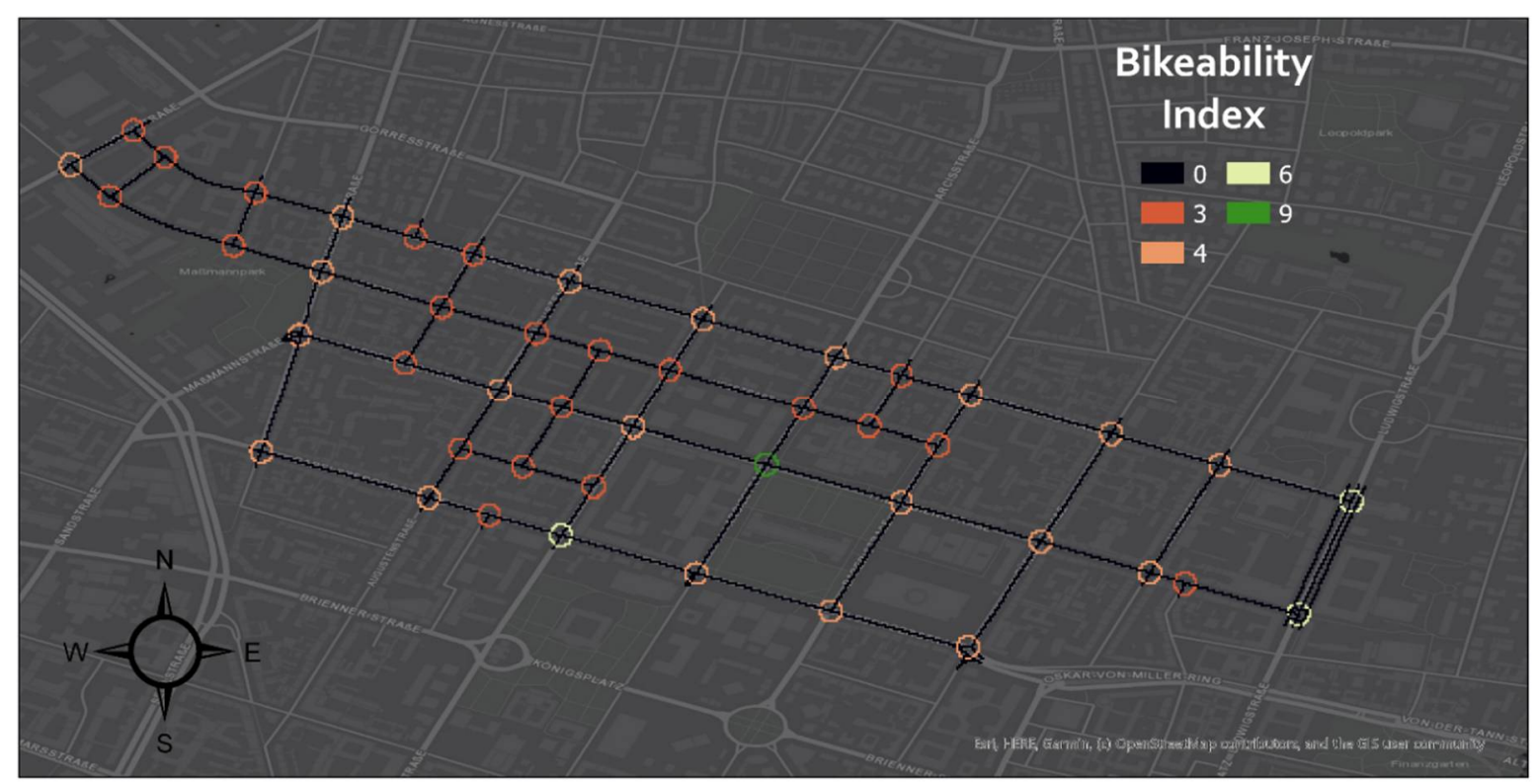

Figure 6. Evaluation of intersections.

As we focused only on the intersections in Figure 6, we incorporated the value zero, which is shown in black for all excluded road segments (segments not belonging to intersections).

The weighted overlay of linear criteria was done with $50 \%$ bicycle infrastructure, $25 \%$ speed limit, and 25\% bicycle parking. We selected these weighting schemes based on interviews conducted with commuting students who were familiar with the investigation area. The basis of the main evaluation were variations of bikeablity index choropleth maps, similar to the ones in Figures 3-6. The street network mostly reached a medium score (visualized in orange and yellow) and only a few segments were rated as good (e.g., Ludwig-, Arcis-, and Lothstraße). This outcome was also welcomed by most of the interviewed commuters. Although the number of persons who participated in this questionnaire was comparably low (fewer than 10), we argue that adjusting the weighted 
overlay could be part of the proposed methodology. Figure 7 shows the emerging visual pattern after adding the raster information of intersections.

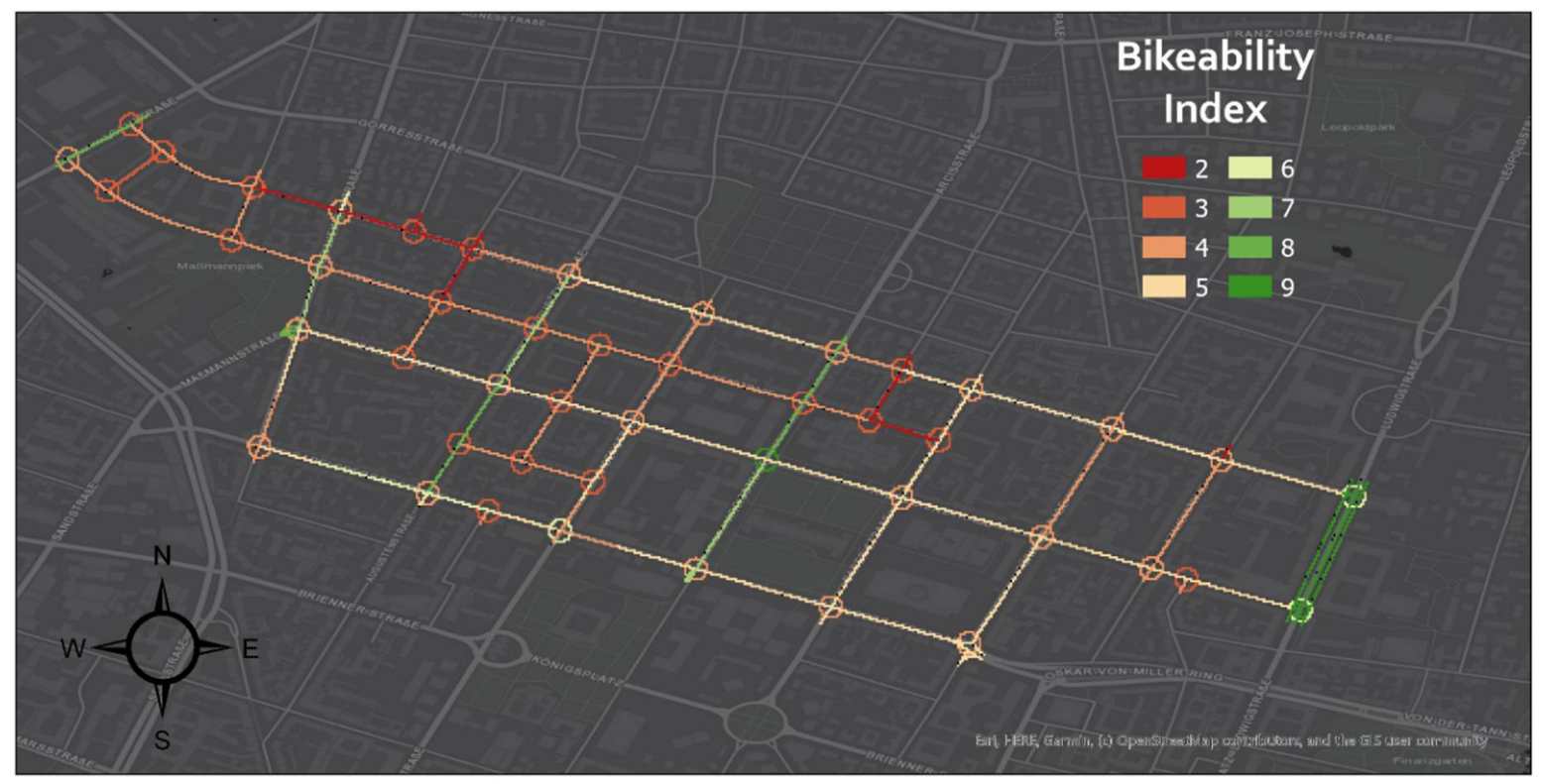

Figure 7. Weighted overlay of linear segments and intersections.

\section{Discussion}

The only segment that scores well in all categories is the Ludwigstraße; the major connection streets of universities (Schelling- and Theresienstraße) are rated mediocre according to this index. The average bikeability is 5.1 and the intersections are rated as 3.8 which is rather poor. The zones with a good bicycle infrastructure seem to have good bikeability overall, i.e., a weighting of $50 \%$ becomes apparent.

This index has its strengths as well as weaknesses. Intersections are scarcely regarded in other indices, yet they are crucial for safety. Furthermore, the independent gathering of data is very accurate and done by only one person, and therefore with the same standard. In particular, the bicycle parking spots in the original data source (OSM) were fragmentarily recorded. The division of the street network is very detailed, and therefore attribute values do not change within one segment. Another benefit is the simplicity of the calculations. With only three weighted factors, the calculation can be quickly done as soon as the data is available.

A disadvantage, however, is that the traffic load is not part of the index. In the case that it is weak, a missing bike path or lane would be less important. Especially shorter streets in living areas would achieve a better overall rating and the contrary would account for longer streets. Another downside is that the field analysis methodology is independent from currentness and quality of geodata, however, it requires significant effort to generate the data. For larger areas, the time investment would increase exponentially.

The map serves as a quick overview of bikeability in part of Munich and shows clearly that the connecting streets between the universities have insufficient bikeability, considering that especially students show great bike affinity. One measure might be to increase the number of junctions with traffic lights and biking boxes or, for example, extend the bike lane in the Gabelsbergerstraße, which abruptly ends, when this one-way street changes from two to three lanes.

\section{Conclusions and Outlook}

Indices for bikeability can normally be divided into four groups, key feature is the differentiation in models with hard infrastructure factors and those with hard and sup- 
plementary factors and whether it is a technical analysis or public survey to gather data. Authors select criteria according to the respective topography of the testing ground, aim of the study, and personal perception of the criteria's importance.

The assessment of the testing area in Munich showed a serious lack of suitable bicycle infrastructure. The fact that some one-way streets are not open to cyclist encourages car drivers to drive fast and also means detours for cyclists, reducing the accessibility of destinations. On the upside, the city council has approved the removal of the one-way street regulation in the Theresien and Gabelsbergerstraße and the building of bicycle infrastructure in the Gabelsbergerstraße [50]. This would increase the bikeability significantly from 5.08 to 5.43 , in the case that all one-way segments were revoked, and bike lanes were installed. A resulting map view would look like that shown in Figure 8.

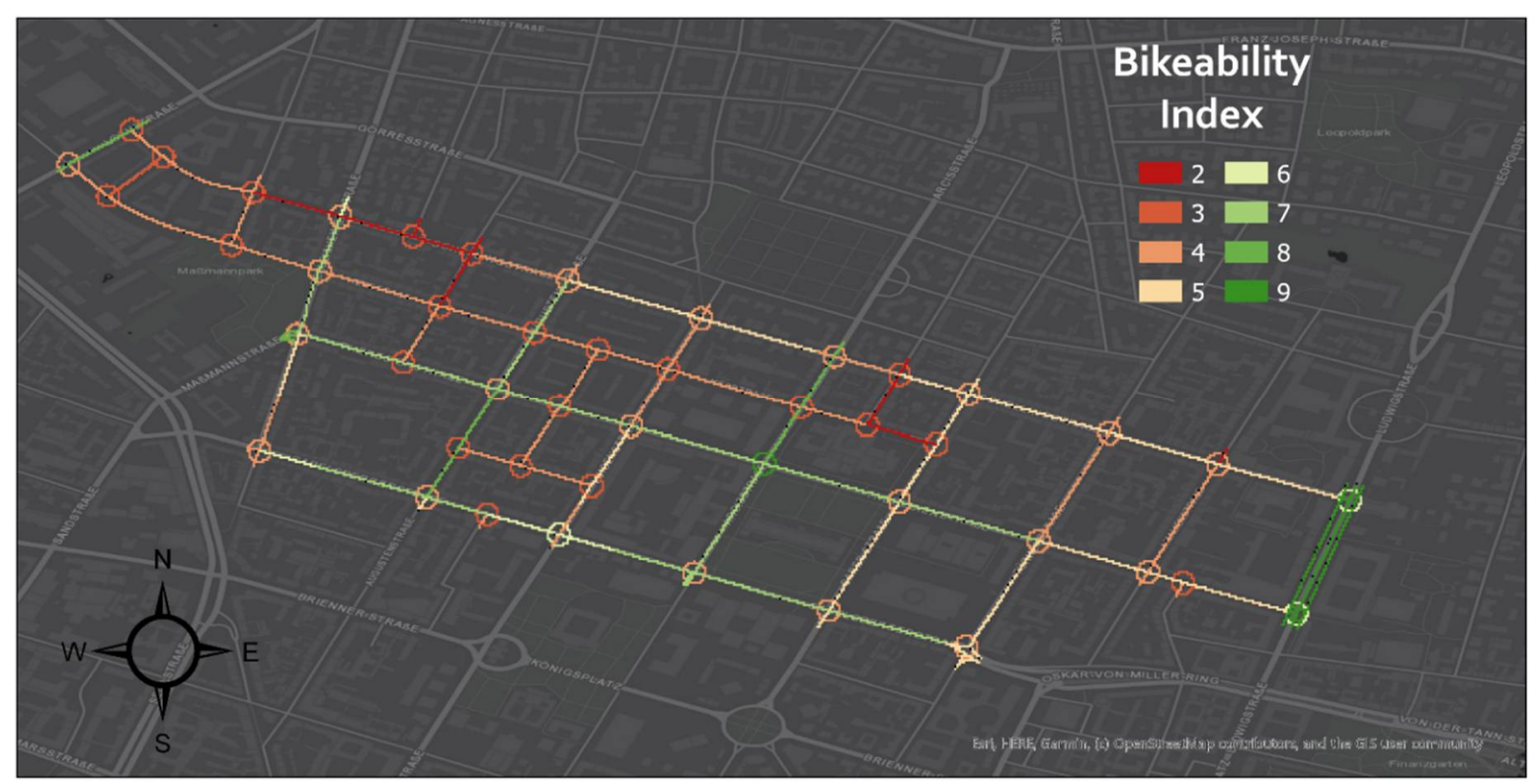

Figure 8. Weighted overlay of linear components incorporating measures in Theresien and Gabelsbergerstraße.

Regarding bicycle parking, there is room for improvement that should be exploited. A general lack of cycle racks is apparent, and roofed or sheltered racks are nonexistent. In particular, people who own new or expensive bikes would not use them during inclement weather. In order to ease traffic situations with frequent congestions and to motivate people to resort to bicycles for everyday routes, incentives must be created. This can be done by increasing safety through implementing physical separation of bike paths and motorized transport paths, opening one-way streets for cyclists to reduce detours, and actively promoting cycling on a political level. Consequently, people would tend to prioritize using bicycles rather than cars and everyone would benefit from better air quality and individual health-related advantages of cycling.

Author Contributions: Conceptualization, J.S.-Q., A.K. and G.G.; methodology, J.S.-Q. and A.K.; formal analysis, J.S.-Q.; resources, J.S.-Q. and A.K.; data curation, J.S.-Q.; writing-original draft preparation, J.S.-Q.; writing —review and editing, J.S.-Q., A.K. and G.G.; visualization, J.S.-Q. and A.K.; supervision, A.K. and G.G. All authors have read and agreed to the published version of the manuscript.

Funding: This work is a result of the research project @CITY Automated Cars and Intelligent Traffic in the City. The project is supported by the Federal Ministry for Economic Affairs and Energy (BMWi), based on a decision taken by the German Bundestag, grant number 19A17015B. The author is solely responsible for the content of this publication.

Institutional Review Board Statement: Not applicable for this study. 
Informed Consent Statement: Not applicable for this study.

Data Availability Statement: The input data in this research can be accessed freely from online sources.

Acknowledgments: The authors gratefully acknowledge the comments and suggestions of the anonymous reviewers, which helped to improve the manuscript.

Conflicts of Interest: The authors declare no conflict of interest. The funders had no role in the design of the study; in the collection, analyses, or interpretation of data; in the writing of the manuscript, or in the decision to publish the results.

\section{Appendix A Evaluation Scales (Cursive Combination Not Present in the Testing Area)}

Table A1. Bicycle infrastructure.

\begin{tabular}{ccc}
\hline $\begin{array}{c}\text { Type of Street or Cycling } \\
\text { Infrastructure }\end{array}$ & $\begin{array}{c}\text { Abbreviation in } \\
\text { Attribute Table }\end{array}$ & Value (1-10) \\
\hline Broad bike path, both-sided & RWb & 10 \\
Broad and narrow bike path & RWb_RWs & 9 \\
Narrow bike path, both-sided & RWs & 8 \\
Cycling street & FS & 7 \\
Narrow bike path and bike lane & RWs_RS & 7 \\
Bike lane, both-sided & RS & 6 \\
Advisory bike lane, both-sided & SSt & 5 \\
Regular street & None & 3 \\
One-way street, open & EBo & 3 \\
One-way street with advisory bike lane & EB_RS & 3 \\
\hline
\end{tabular}

Table A2. Speed limit.

\begin{tabular}{cc}
\hline Maximum Speed & Value (1-10) \\
\hline $30 \mathrm{~km} / \mathrm{h}$ & 10 \\
$50 \mathrm{~km} / \mathrm{h}$ & 7 \\
\hline
\end{tabular}

Table A3. Bicycle parking.

\begin{tabular}{cc}
\hline Type of Parking Facility & Value (1-10) \\
\hline Bike Locker & 10 \\
Roofed bike rack & 8 \\
Regular bike rack & 6 \\
No bike rack & 2 \\
\hline
\end{tabular}

Table A4. Intersections.

\begin{tabular}{lcc}
\hline \multicolumn{1}{c}{ Type of Intersection } & $\begin{array}{c}\text { Abbreviation in Attribute } \\
\text { Table }\end{array}$ & Value (1-10) \\
\hline $\begin{array}{l}\text { Traffic light width biking box } \\
\begin{array}{l}\text { Designated cycling traffic } \\
\text { light }\end{array}\end{array}$ & BB & 9 \\
$\begin{array}{l}\text { Traffic light with visual } \\
\text { markers on the ground }\end{array}$ & FA & 6 \\
$\begin{array}{l}\text { Regular traffic light } \\
\text { Regular intersection without }\end{array}$ LSA_M & 6 \\
traffic lights & LSA & 3 \\
\hline
\end{tabular}




\section{References}

1. Karanikola, P.; Panagopoulos, T.; Tampakis, S.; Tsantopoulos, G. Cycling as a smart and green mode of transport in small touristic cities. Sustainability 2018, 10, 268. [CrossRef]

2. Faghih-Imani, A.; Anowar, S.; Miller, E.J.; Eluru, N. Hail a cab or ride a bike? A travel time comparison of taxi and bicycle-sharing systems in New York City. Transp. Res. Part A Policy Pract. 2017, 101, 11-21. [CrossRef]

3. Horton, D. Environmentalism and the bicycle. Environ. Politics 2006, 15, 41-58. [CrossRef]

4. Christensen, H.R. Is the Kingdom of bicycles rising again? Cycling, gender, and class in postsocialist China. Transfers 2017, 7, 1-20. [CrossRef]

5. De Nazelle, A.; Nieuwenhuijsen, M.J.; Antó, J.M.; Brauer, M.; Briggs, D.; Braun-Fahrlander, C.; Cavill, N.; Cooper, A.R.; Desqueyroux, H.; Fruin, S. Improving health through policies that promote active travel: A review of evidence to support integrated health impact assessment. Environ. Int. 2011, 37, 766-777. [CrossRef] [PubMed]

6. Pucher, J.; Buehler, R. Making cycling irresistible: Lessons from the Netherlands, Denmark and Germany. Transp. Rev. 2008, 28, 495-528. [CrossRef]

7. Lee, J.-S.; Jiang, J.-W. Enhanced fuzzy-logic-based power-assisted control with user-adaptive systems for human-electric bikes. IET Intell. Transp. Syst. 2019, 13, 1492-1498. [CrossRef]

8. Gössling, S. Urban transport justice. J. Transp. Geogr. 2016, 54, 1-9. [CrossRef]

9. Rietveld, P. Biking and Walking: The Position of Non-Motorized Transport Modes in Transport Systems. In Handbook of Transport Systems and Traffic Control; Button, K.J., Hensher, D.A., Eds.; Emerald Group Publishing Limited: Bingley, UK, 2001.

10. Hoedl, S.; Titze, S.; Oja, P. The bikeability and walkability evaluation table: Reliability and application. Am. J. Prev. Med. 2010, 39, 457-459. [CrossRef]

11. Winters, M.; Teschke, K.; Brauer, M.; Fuller, D. Bike Score ${ }^{\circledR}$ : Associations between urban bikeability and cycling behavior in 24 cities. Int. J. Behav. Nutr. Phys. Act. 2016, 13, 18. [CrossRef]

12. Krenn, P.J.; Oja, P.; Titze, S. Development of a bikeability index to assess the bicycle-friendliness of urban environments. Open J Civ. Eng. 2015, 5, 451. [CrossRef]

13. Merriam-Webster.com. Available online: https://www.merriam-webster.com/dictionary/bikeability (accessed on 31 March 2019).

14. Oxforddictionaries.com. Available online: https:/ / en.oxforddictionaries.com/definition/bikeable (accessed on 31 March 2019).

15. Lowry, M.B.; Callister, D.; Gresham, M.; Moore, B. Assessment of communitywide bikeability with bicycle level of service. Transp. Res. Rec. 2012, 2314, 41-48. [CrossRef]

16. Festa, D.C.; Forciniti, C. Attitude towards bike use in Rende, a small town in south Italy. Sustainability 2019, 11, 2703. [CrossRef]

17. Mora, R.; Moran, P. Public Bike Sharing Programs under the Prism of Urban Planning Officials: The Case of Santiago de Chile. Sustainability 2020, 12, 5720. [CrossRef]

18. Shaaban, K. Why Don't People Ride Bicycles in High-Income Developing Countries, and Can Bike-Sharing Be the Solution? The Case of Qatar. Sustainability 2020, 12, 1693. [CrossRef]

19. Nielsen, T.A.S.; Skov-Petersen, H. Bikeability-Urban structures supporting cycling. Effects of local, urban and regional scale urban form factors on cycling from home and workplace locations in Denmark. J. Transp. Geogr. 2018, 69, 36-44. [CrossRef]

20. Di Mascio, P.; Fusco, G.; Grappasonni, G.; Moretti, L.; Ragnoli, A. Geometrical and functional criteria as a methodological approach to implement a new cycle path in an existing urban road network: A case study in Rome. Sustainability 2018, 10, 2951. [CrossRef]

21. Shui, C.; Chan, W. Optimization of a bikeway network with selective nodes. Sustainability 2019, 11, 6531. [CrossRef]

22. Keler, A.; Schmiedlau, F.; Grigoropoulos, G. Evaluating bicycle traffic efficiency using bicycle traffic counts at sparse locations in cities-comparing NYC with Munich. In Proceedings of the GISRUK 2020-28th GIS Research UK Conference, London, UK, 21-23 June 2020.

23. Lin, S.-J.; Shyu, G.-S.; Fang, W.-T.; Cheng, B.-Y. Using multivariate statistical methods to analyze high-quality bicycle path service systems: A case study of popular bicycle paths in Taiwan. Sustainability 2020, 12, 7185. [CrossRef]

24. Ryu, S. A Bicycle Origin-Destination Matrix Estimation Based on a Two-Stage Procedure. Sustainability 2020, 12, 2951. [CrossRef]

25. Hardinghaus, M.; Papantoniou, P. Evaluating Cyclists' Route Preferences with Respect to Infrastructure. Sustainability 2020, 12, 3375. [CrossRef]

26. Yao, Y.; Zhang, Y.; Tian, L.; Zhou, N.; Li, Z.; Wang, M. Analysis of Network Structure of Urban Bike-Sharing System: A Case Study Based on Real-Time Data of a Public Bicycle System. Sustainability 2019, 11, 5425. [CrossRef]

27. Boettge, B.; Hall, D.M.; Crawford, T. Assessing the Bicycle Network in St. Louis: A PlaceBased User-Centered Approach. Sustainability 2017, 9, 241. [CrossRef]

28. Furth, P.G.; Mekuria, M.C.; Nixon, H. Network Connectivity for Low-Stress Bicycling. Transp. Res. Rec. 2016, 2587, 41-49. [CrossRef]

29. Useche, S.; Montoro, L.; Alonso, F.; Oviedo-Trespalacios, O. Infrastructural and human factors affecting safety outcomes of cyclists. Sustainability 2018, 10, 299. [CrossRef]

30. Ul-Abdin, Z.; De Winne, P.; De Backer, H. Risk-perception formation considering tangible and non-tangible aspects of cycling: A flemish case study. Sustainability 2019, 11, 6474. [CrossRef]

31. Shaaban, K.; Abdur-Rouf, K. Assessing Walking and Cycling around Schools. Sustainability 2020, 12, 10607. [CrossRef] 
32. Vasilev, M.; Pritchard, R.; Jonsson, T. Trialing a Road Lane to Bicycle Path Redesign—Changes in Travel Behavior with a Focus on Users' Route and Mode Choice. Sustainability 2018, 10, 4768. [CrossRef]

33. Nikitas, A. How to save bike-sharing: An evidence-based survival toolkit for policy-makers and mobility providers. Sustainability 2019, 11, 3206. [CrossRef]

34. Sun, Y.; Mobasheri, A.; Hu, X.; Wang, W. Investigating impacts of environmental factors on the cycling behavior of bicycle-sharing users. Sustainability 2017, 9, 1060. [CrossRef]

35. Macioszek, E.; Świerk, P.; Kurek, A. The Bike-Sharing System as an Element of Enhancing Sustainable Mobility-A Case Study based on a City in Poland. Sustainability 2020, 12, 3285. [CrossRef]

36. Lee, K.; Chae, J.; Kim, J. A courier service with electric bicycles in an Urban Area: The case in Seoul. Sustainability 2019, 11, 1255. [CrossRef]

37. Copenhagenize_Design_Company. The Copenhagenize Bicycle Friendly Cities Index. 2017. Available online: http: / / copenhagenizeindex.eu/about.html (accessed on 31 March 2019).

38. Kazemzadeh, K.; Laureshyn, A.; Winslott Hiselius, L.; Ronchi, E. Expanding the Scope of the Bicycle Level-of-Service Concept: A Review of the Literature. Sustainability 2020, 12, 2944. [CrossRef]

39. Adfc.de. ADFC-Fahrradklima-Test. 2018. Available online: https://www.fahrradklima-test.de/ (accessed on 31 March 2019).

40. McHarg, I.L.; History, A.M.O.N. Design with Nature; American Museum of Natural History: New York, NY, USA, 1969.

41. Tomlin, C.D. Map algebra: One perspective. Landsc. Urban Plan. 1994, 30, 3-12. [CrossRef]

42. Gehring, M.S.D.B. Bikeability-Index für Dresden—Wie Fahrradfreundlich ist Dresden? Available online: https://tud.qucosa. de/api/qucosa\%3A30317/attachment/ATT-0/ (accessed on 31 March 2019).

43. Jonietz, D.; Timpf, S. Entwicklung eines GIS-basierten Bikeablity-Index am Beispiel der Stadt Augsburg. In Geoinformatik; Shaker: Aachen, Germany, 2012; pp. 83-90.

44. Zhu, S.; Zhu, F. Cycling comfort evaluation with instrumented probe bicycle. Transp. Res. Part A Policy Pract. 2019, 129, $217-231$. [CrossRef]

45. Gholamialam, A.; Matisziw, T.C. Modeling bikeability of urban systems. Geogr. Anal. 2019, 51, 73-89. [CrossRef]

46. Geofabrik.de. Available online: https://download.geofabrik.de/europe/germany/bayern/oberbayern.html (accessed on 31 March 2019).

47. Wahlgren, L.; Schantz, P. Bikeability and methodological issues using the active commuting route environment scale (ACRES) in a metropolitan setting. BMC Med. Res. Methodol. 2011, 11, 6. [CrossRef]

48. Fraser, A. An Empirical Study of Bicyclists' Turning Behaviour at Signalized Intersections. Master's Thesis, University of Waterloo, Waterloo, ON, Canada, 23 August 2018.

49. Mayfield, C.J.; Kumler, M.; Afzalan, N. Automating the Classification of Thematic Rasters for Weighted Overlay Analysis in GeoPlanner for ArcGIS. Master's Thesis, University of Redlands, Redlands, CA, USA, February 2016.

50. Kunstareal-Modifizierte Alternative 5 Im 3. Stadtbezirk Maxvorstadt. Available online: https:/ /www.muenchen-transparent. de/dokumente/3651443 (accessed on 31 March 2019). 